\title{
Advantages of twin rudder system with asymmetric wing section aside a propeller
}

\author{
The new hull form with twin rudders utilizing duct effects
}

\author{
Noriyuki Sasaki $^{1} \cdot$ Mehmet $^{\text {Atlar }^{1}} \cdot$ Sadatomo Kuribayashi $^{2}$
}

Received: 13 July 2015/ Accepted: 28 October 2015/Published online: 29 December 2015

(C) The Author(s) 2015. This article is published with open access at Springerlink.com

\begin{abstract}
This study presents a new twin rudder system with asymmetric wing section, aside a propeller, as a new category energy saving device (ESD) for ships. The energy saving principle of the new ESD, which is called "Gate rudder", is described and its applicability on a large bulk carrier is explored using experimental and numerical methods. The study makes emphasis on the cost-effectiveness of the proposed ESD and presents a potential energy saving up to 7-8 \% with the new device as well as an attractive return investment in $0.37-0.9$ year. These estimations are based on the conventional powering methods, whereas the accuracy of the ESD design method is confirmed by model test measurements.
\end{abstract}

Keywords Twin rudder - Gate rudder - Duct effect . ESD $\cdot$ Maneuverability

\section{Introduction}

Increased ship energy efficiency is paramount in mitigating $\mathrm{CO}_{2}$ emissions from shipping. Consequently, substantial amount of energy saving measures has been proposed but so far only cost-effective proposals have been able to survive. Based on this fact, before elaborating on the costeffectiveness of an energy saving measure, one may ask what is the cost-effectiveness and how it can be justified.

Within the framework of an energy saving system, it is a fact that more complex of an energy saving system is, more

Noriyuki Sasaki

noriyuki.sasaki@ncl.ac.uk

1 Newcastle University, Newcastle upon Tyne, UK

2 Kuribayashi Steam Ship Co. Ltd., Tokyo, Japan difficult to evaluate. This has been also the case for many energy saving devices (ESD) for ships when they were first invented and fitted on ships based on completely new ideas without paying much attention to their simplicity and user friendliness.

Costing of a new device can be estimated in two categories: (a) Pre-installation costs; (b) Post-installation costs. The former includes the fees for design, manufacture and installation while the latter is the maintenance fees of the device during its service life. If the new ESD requires additional instrumentation or power, the cost estimation is not so easy and the ship owner may require compensation for the risk of unexpected accidents before making commitment to its installation. The post-installation costs also strongly depend on other factors including ship type, size, navigation route and number of crew.

In this paper, a new ESD, which is known to be "gate rudder", is introduced for a conventional bulk carrier and its applicability and economic evaluation are investigated. The evaluation is conducted in technical and economical sense because, although the new ESD is based on a simple technical ground, it has many other aspects to evaluate after the installation including its cost of return that is most important.

Conventional ESDs can be categorized as in the following two groups or combination of them based on their energy saving principles:

(1) Recovery of propeller rotational losses by fins which are placed in front or after a propeller (i.e., pre- or post-swirl devices).

(2) Recovery of viscous resistance losses by ducts or fins which are placed in front of a propeller so as to generate (an improve) the thrust (i.e., flow improvement or wake equalizing device). 


\section{Conventional ESDs}

Figure 1 presents a summary of many different types of ESDs since 1980 s to today. Around 1980, already two types of ESDs were invented in Japan. First one is the reaction fin of Mitsubishi Heavy Industries [1] which belongs to group (1). Second one is SAF [2] (Sumitomo Arched Fin) of Sumitomo Heavy Industries which belongs to group (2). The purpose of using reaction fin is to recover propeller rotational losses by pre-swirl fins in front of a propeller. In that the key issue is to design and place the fins so as not to generate the excess resistance or to generate the thrust. Sumitomo Arched Fin (SAF) was invented and installed on a large tanker in the beginning of 1980s to improve the flow field around the propeller and consequently to improve the propulsion factors without spoiling the ship resistance by the arched fin. In this concept, the key issue is also to design the fin so as to generate thrust by accelerating the flow at the under part of the fin. This semicircular fin can be regarded as part of a duct and based on the similar concept several ducts were invented such as WED, SSD, SILD, Mewis duct and weather adopted duct (WAD). The first complete small duct in front of a propeller was the wake equalizing duct (WED) [3] which was applied on many vessels because of its simplicity. The most sophisticated duct of this type is super stream duct (SSD) $[4,5]$ which can minimize the resistance of the duct itself using a wing shape ring (duct).

Next unique ESD is down flow preventing fin (DPF) of Sumitomo Heavy Industries which was installed on a VLCC in 1990. The aim of the fin is to increase the pressure distribution at the end of stern and reduce swirling flow of the same direction as the propeller rotation by obstructing the flow by the horizontal fin. This type of fin is very cost effective and the performance was much improved from the beginning as reported by many shipbuilding companies [6, 7]. Therefore, many types of horizontal fins have been applied to the actual vessels.

Sumitomo integrated lammeren duct (SILD) is a first ESD which combined two concepts [group (1) and group (2)] and installed on a VLCC [8]. Inside a circular duct, twisted fore stators were installed to produce a swirling flow of opposite direction to the propeller rotation. The performance of this ducted system strongly depends on the stern shape and it seems that a vessel with the stern bulb is likely to save fuel more than V-shaped stern or a stern with a sole piece.

Rudder bulb system (RBS) [9] is another type of ESD belonging to group (1). RBS can recover propeller rotational energy losses by fins and it can reduce a rudder resistance by regulating a flow around the rudder leading edge. Although it does not appear in Fig. 1, propeller boss cap fin (PBCF) [10] is another ESD working based on the same mechanism. However, the effect is limited because it is fitted onto the small propeller boss cap. Similarly, although, there is no photo of contra-rotating propeller (CRP) in Fig. 1, it is the most well-known propulsor type belongs to group (1).

As one can see in Fig. 1, most ESDs can be included either in group (1) or group (2) or their combination. In the meantime, there are three ESDs which are also included in Fig. 1 and considered saving energy based on somehow different principles. Amongst them STEP was invented at NMRI and it is installed on the bow to reduce wave resistance due to severe weather conditions [11]. Therefore, the energy saving can be observed only for the weather conditions higher than BF5 (wave height $>2 \mathrm{~m}$ ). It can be said that WAD belongs to the same category to STEP in the aspect of energy saving. For this device, the focus is on the actual sea conditions instead of calm sea
Fig. 1 Typical ESDs from 1980 to today

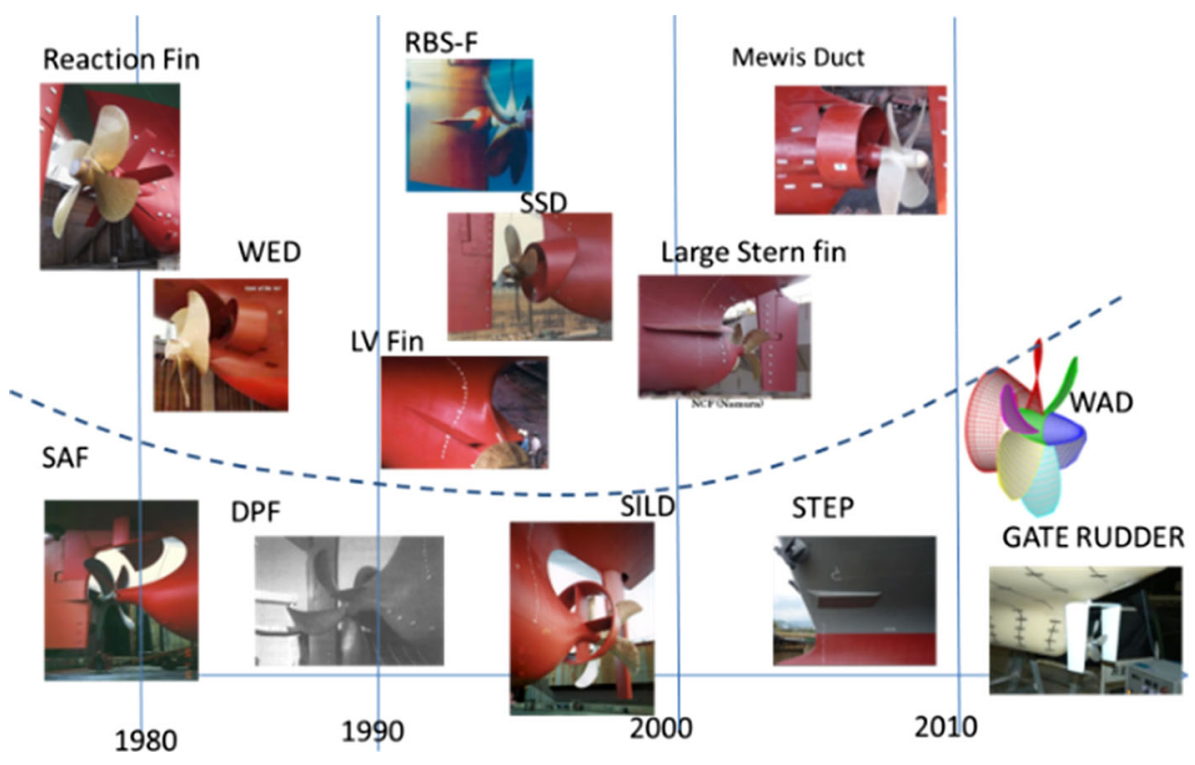


condition such as during trials. WAD is almost the half size of a conventional duct type WSD; however, it will increase the performance at actual sea conditions [12].

One should bear in mind that, depending on the location of an ESD before or after the propeller, the flow at the propeller plane can be affected adversely and consequently the propeller may have a risk of cavitation and noise problem. This risk will be increased if one prefers to obtain higher propulsive efficiency by enlarging the characteristic length or diameter of the $\operatorname{ESD}(\mathrm{s})$. Finally, in Fig. 1, the
ESDs under the dotted line were invented by the Principal Author of this paper, including the twin rudder system with asymmetric section which is described in the next.

\section{Twin rudder system with asymmetric section}

Amongst so many different types of ESDs in the market, the twin rudder system (gate rudder) proposed in this paper is quite different from the existing ESDs with its
Fig. 2 Typical conventional rudders [13]

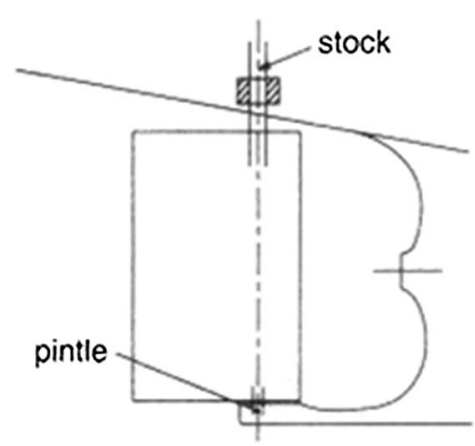

(a) Balanced rudder

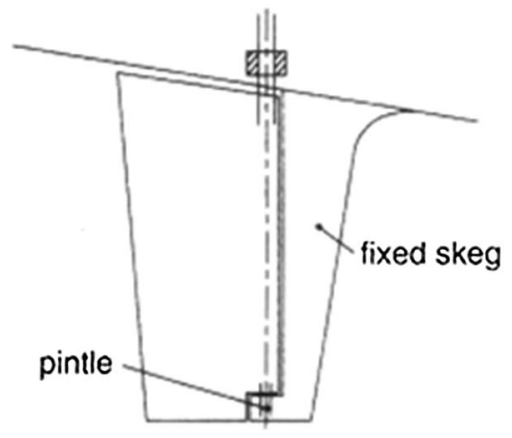

(c) Full skeg rudder (Unbalanced)

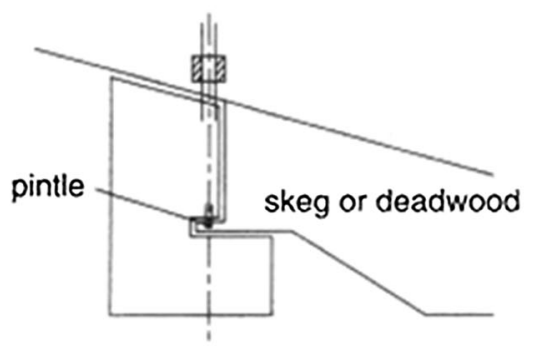

(e) Semi-balanced, aft of skeg or deadwood (f) Aft of keel or deadwood (unbalanced)

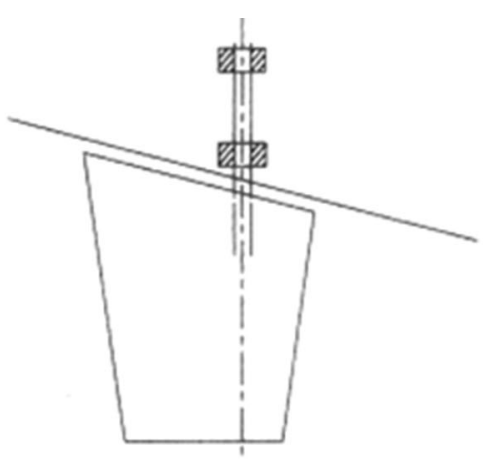

(b) Spade rudder

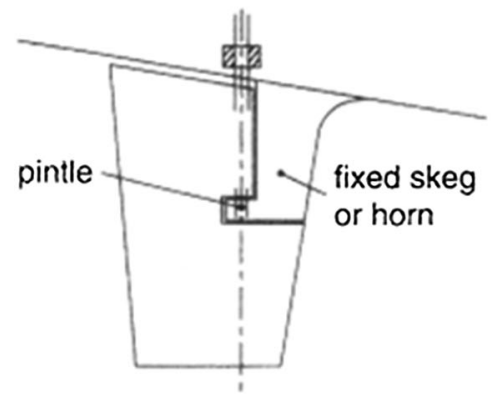

(d)Semi-balanced skeg rudder

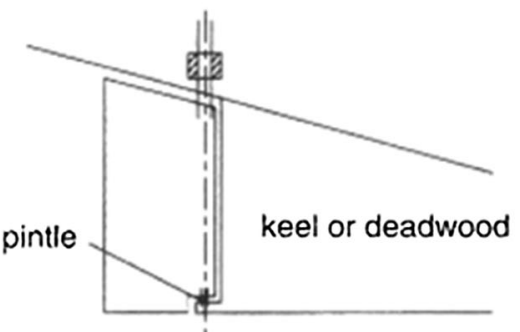

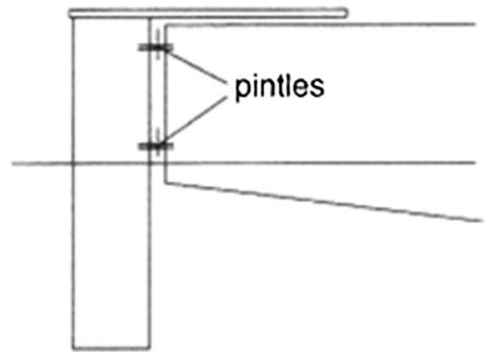

(g) Transom hung-surface piercing 
Table 1 Principal dimensions

\begin{tabular}{lll}
\hline & Conventional & Gate rudder \\
\hline Lpp & $300 \mathrm{~m}$ & \\
$B$ & $65.0 \mathrm{~m}$ & \\
$d$ & $17.9 \mathrm{~m}$ & \\
$\mathrm{C}_{\mathrm{B}}$ & 0.8 & \\
M/E O/P & $20,800 \mathrm{~kW} \times 99 \mathrm{RPM}$ & \\
Prop. dia. & $8.5 \mathrm{~m}$ & Gate rudder \\
Rudder & Conventional &
\end{tabular}

asymmetric cross-section which works on a different principle than the existing types. The major advantage of the gate rudder system stems from the duct effect originated from the working propeller. By placing two asymmetric rudders at each side of a propeller, the rudders and the propeller are able to function like a ducted propeller. In addition to the increased propulsive efficiency due to the accelerated duct flow, the rotatable twin rudder system of the new ESD also provides improved maneuverability, and seakeeping ability. Although these advantages will be further elaborated in the paper, the following list summarizes the advantages of the gate rudder in three categories:

Economical:

1. higher propulsive efficiency owing to the duct effect

2. avoiding a torque-rich condition by slight change in rudder angles

3. increase of cargo space by shifting the engine room further

4. reduction of ship length, if necessary, by elimination of a conventional rudder

Safety:

5. remarkable stopping ability

6. remarkable maneuverability utilizing rotatable twin rudders independently

7. remarkable berthing performance (in crabbing mode)

8. reduction of the rolling motion by controlling the rudder angles

Habitability:

10. reduction of propeller-induced noise and vibration by improved stern flow (i.e., wake equalizing effect)

11. increased cargo space by shifting the engine room afterward

12. reduction of ship length, if necessary, by elimination of a conventional rudder.

There are many variations of rudder configurations as shown in Fig. 2 as summarized by Molland and Turnock [13]. However, the configuration of twin rudders aside of a propeller is rarely seen except twin rudders with simple symmetric section to improve the flow separation at the stern part of a vessel together with the action of the propeller [14].

By applying asymmetric rudder sections with cambers towards the ship center and by shifting the rudderpost to an appropriate forward position, this new twin rudder system begins to show many of the above-listed advantages.

As summarized earlier, the twin rudders proposed here have many advantages and it is not easy to evaluate each of them individually since a lot of interrelated synergy effects can be expected among these advantages.

The Authors have developed a special rudder named "gate rudder" which is shown in Figure as part of one of the projects conducted at National Maritime Research Institute (NMRI) and it has been confirmed that the energy saving of the gate rudder in combination with the propeller can be of $6-8 \%$ for the vessel with high block coefficient or lower L/B ratio. The proposed gate rudder concept can improve the disadvantage of conventional rudder for maneuverability during port operations such as a berthing. This ability is very essential and important especially for small ships operating in the coastal areas due to the limited port spaces available and lack of support services.

This disadvantage is further accentuated by the fact that the rudder system may not be placed in the high velocity slipstream of the propeller by which the rudder is able to generate a strong lateral force.

This paper will review a recently conducted bulk carrier project with the gate rudder system and further evaluate this ESD configuration with a specific emphasis on its economical evaluation.

\section{Large bulk carrier project}

\subsection{Background}

It is a well-known fact that all the conventional rudders are located behind a propeller to make use of the propeller slipstream effectively to control the ship. If the rudder will not be used as a controlling device, no one will consider placing the rudder behind the propeller because of the larger lateral force and the larger distance from the center of ship motion. In addition, a rudder will have further adverse effect on propulsive efficiency and create vibration and noise resulting from amplified propeller cavitation by the displacement effect of the rudder. Moreover, the capacity of the vessel can be reduced by the presence of the rudder pushing the engine room of a vessel forward. Therefore, if a rudder can be replaced by another control surface, which has no adverse effect on the ship functions, many advantages 


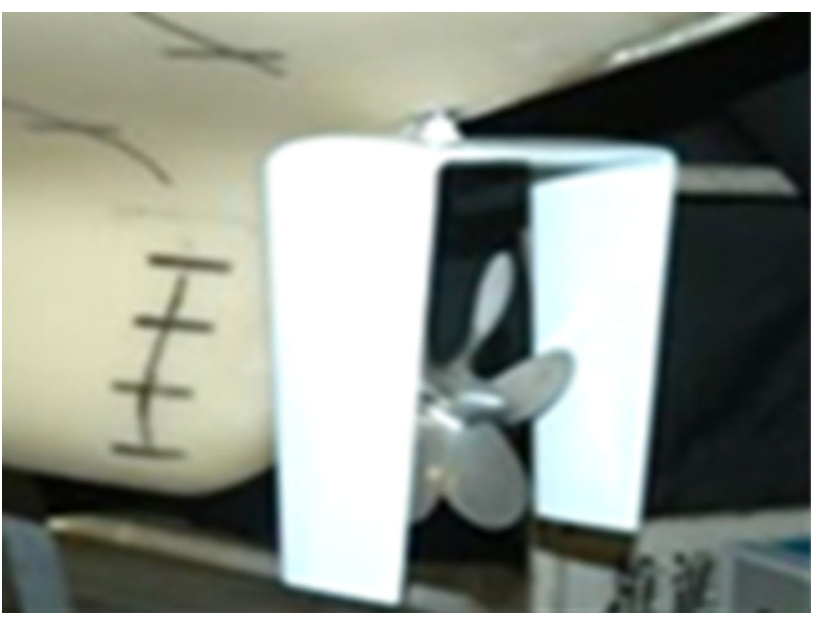

Fig. 3 Model gate rudder fitted to ship model

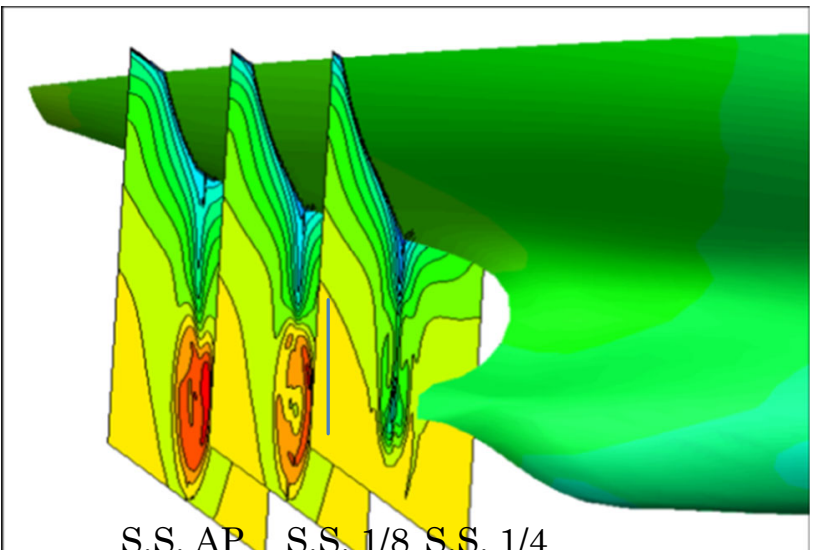

S.S. AP S.S. $1 / 8$ S.S. $1 / 4$

Fig. 4 Stern Flow Calculated by CFD (propeller working condition)

more than we expect will be obtained. Especially in the case of high-speed vessels, the resistance of rudder is relatively high and not negligible. This fact is very important to consider the alternative control surface instead of conventional rudders because the rudder position is less important for this kind of vessel compared with vessels with beamy ships.

To address at the above issues, it is proposed to remove a conventional rudder from its AP position and replace by two small rudders besides the propeller. By this innovative idea, many of advantages mentioned in the previous paragraph will be captured. As stated earlier, this new rudder configuration has been named as "gate rudder" since the top of the rudder configuration has a horizontal section like a gate and this is introduced partly to connect the two small rudders, and partly to provide a larger helm angle range. Principal dimensions of the subject bulk carrier are given in Table 1.

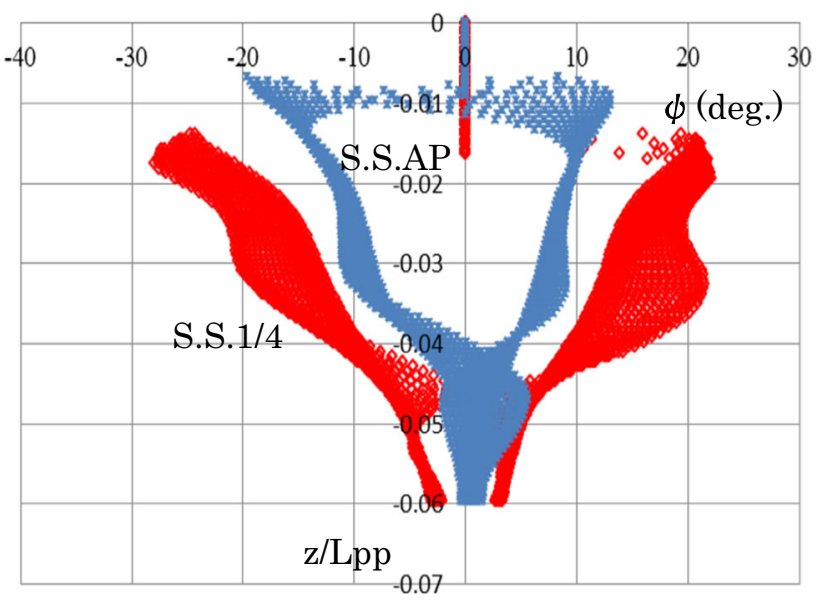

Fig. 5 Calculated horizontal flow angles $(\psi)$

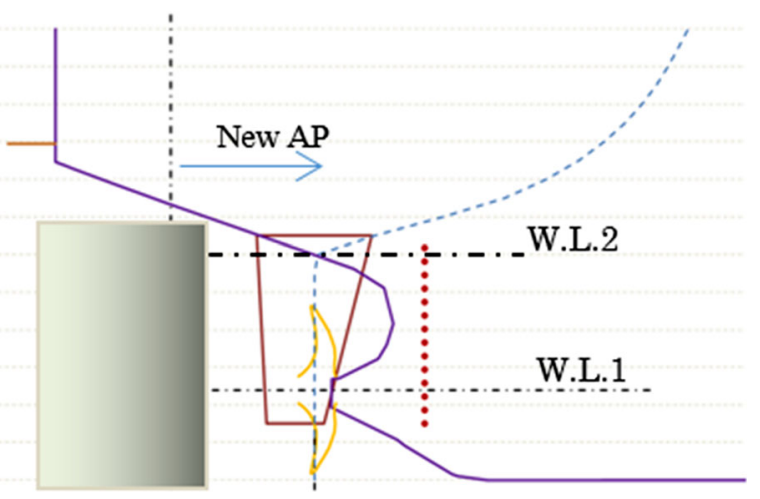

Fig. 6 Rudder design (side view) (a conventional rudder will be removed)

\subsection{Rudder design}

Generally speaking, rudders are designed to have minimum areas within an allowable range of maneuverability. They are not designed to keep the optimum attack angles against the stern flow.

In Fig. 3, the stern of the bulk carrier model, which is used for the application of the gate rudder, can be seen together with the model gate rudder. The flow field around the various sections of this vessel is computed using a CFD code, which is called NEPTUNE developed by NMRI, and results are presented in Figs. 4 and 5.

As shown in Fig. 4 through the computations at Ship Section (S.S.) of AP, $1 / 8$ and $1 / 4$, the rudder works as an efficient wing at the design speed including the action of the propeller. In fact, the acceleration of the propeller is remarkable after S.S. 1/8 indicating that the thickness of the boundary layer at S.S. $1 / 4$ is narrowed by the 


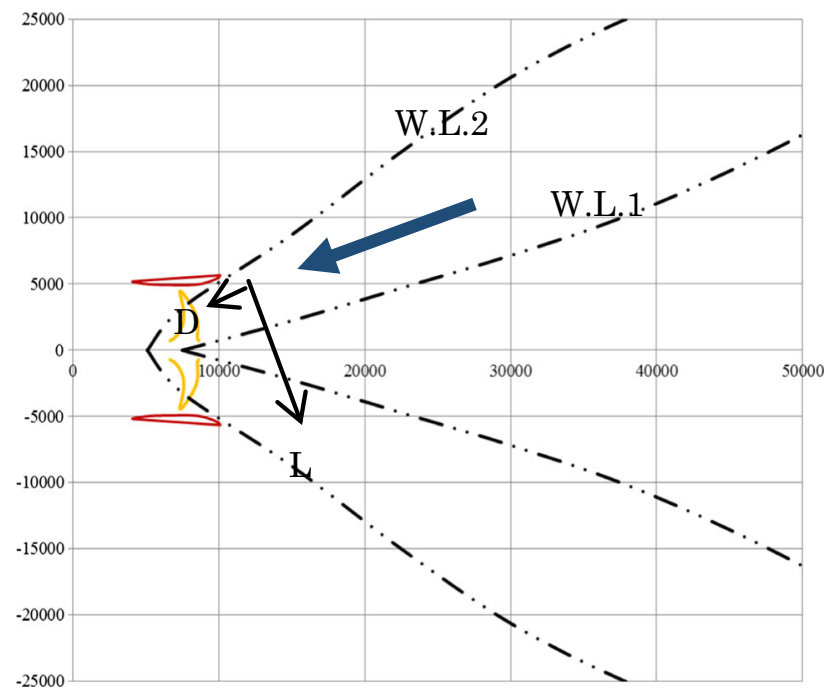

Fig. 7 Rudder design (plan view)

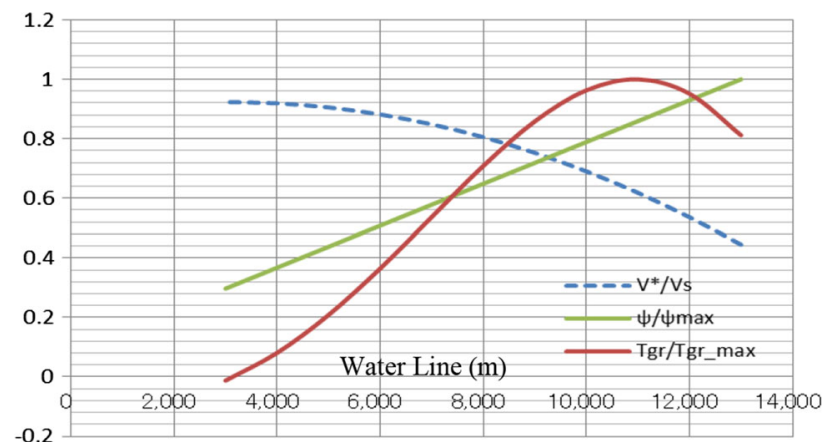

Fig. 8 Span-wise non-dimensional rudder thrust (Tgr/Tgr_max)

propeller's action. Figure 5 shows the flow angles defined by Eq. 5 which are calculated based on Fig. 4 . The maximum flow angles can be seen at $z / \mathrm{Lpp}=-0.035(7.4 \mathrm{~m}$ WL).

The comparison of the propulsive power of the vessel with the gate rudder and conventional rudder was made and it was found that the power saving by the gate rudder over the conventional type was 5-6\%.

Figures 6 and 7 show the side and plan views of the vessel with the gate rudder. As shown in these figures, one can easily configure that the rudder will work as an efficient wing section. To investigate the mechanism of the power saving by a gate rudder, measurement of three components of the rudder forces (moment) and CFD calculations were made. According to the blade element theory, and by neglecting the induced velocity from the each wing section, the rudder forces and moment was calculated and compared later with the experiments.

The calculation of a gate rudder thrust $\left(T_{\mathrm{GR}}\right)$ can be made based on Eq. 1

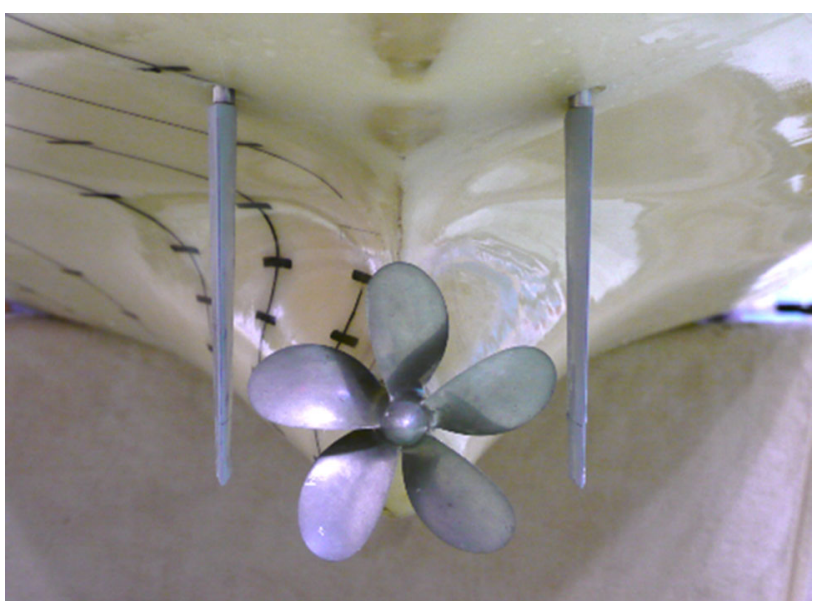

Fig. 9 Aft view of gate rudder

$T_{\mathrm{GR}}=\int_{\mathrm{btm}}^{\mathrm{top}}[L(z) \cos \psi(z)-D(z) \sin \psi(z)] \mathrm{d} z-R_{\mathrm{SFT}}$

where $R_{\mathrm{SFT}}$ indicates the resistance of the rudder stocks which are exposed to the flow and this is relatively large compared with the resistance of the conventional rudder stock because the flow velocity at the gate rudder is almost equal to the ship speed. $L$ and $D$ represent the lift and drag, respectively, and described as in Eqs. 2 and 3:

$L(z)=\frac{1}{2} \rho V^{* 2} \times C_{L}(z) \times c(z)$

$D(z)=\frac{1}{2} \rho V^{* 2} \times C_{D}(z) \times c(z)$

$V^{*}=\sqrt{V_{X}^{2}+V_{Y}^{2}}$

$\psi=\tan ^{-1}\left(\frac{V_{Y}}{V_{X}}\right)$

where lift coefficient $\left(C_{L}\right)$ and drag coefficient $\left(C_{D}\right)$ are given in Eqs. 6 and 7

$C_{L}(z)=2 \pi \sin \left(\psi-\alpha_{0}\right) \frac{\lambda}{2.2+\lambda}$

$C_{D}(z)=2 \times C_{F} \times\left(1+\frac{t(z)}{c(z)}\right)+\left(\frac{t(z)}{c(z)}\right)^{2}+C_{D i}$

$C_{D i}=\kappa \frac{C_{L}^{2}}{\pi \lambda}$

Figure 7 can help for understanding the direction of the flow and force components in the above descriptions.

In a gate rudder configuration, the rudder sections and their nose to tail line directions are the most important design parameters. Before making the model of the gate rudder, one should pay attention to the flow field around 
Table 2 Predicted rudder thrust by Eq. 1

\begin{tabular}{lllllllllllll}
\hline$Z_{\mathrm{m}}$ & $C_{\mathrm{m}}$ & $t_{\max }$ & $\alpha$ & $V^{*}$ & $C_{L}$ & $R_{\mathrm{n}}$ & $\mathrm{CF}$ & $t / c$ & $\mathrm{C}_{D}+\mathrm{C}_{d i}$ & $F x / m$ & $F_{R X}(z)$ & $F_{R Y}(\mathrm{z})$ \\
\hline 0.260 & 0.120 & 0.0168 & 16.87 & 0.444771 & 1.604723 & $3.948 \mathrm{E}+05$ & $2.112 \mathrm{E}-03$ & 0.1400 & 0.2088 & 0.453 & 0.812 & 1.906 \\
0.240 & 0.114 & 0.01593 & 15.41 & 0.536318 & 1.469325 & $4.522 \mathrm{E}+05$ & $1.973 \mathrm{E}-03$ & 0.1397 & 0.1786 & 0.531 & 0.952 & 2.418 \\
0.220 & 0.108 & 0.01506 & 13.95 & 0.618163 & 1.332972 & $4.938 \mathrm{E}+05$ & $1.888 \mathrm{E}-03$ & 0.1394 & 0.1510 & 0.558 & 1.000 & 2.768 \\
0.200 & 0.102 & 0.01419 & 12.49 & 0.690306 & 1.195752 & $5.208 \mathrm{E}+05$ & $1.839 \mathrm{E}-03$ & 0.1391 & 0.1259 & 0.537 & 0.963 & 2.932 \\
0.180 & 0.096 & 0.01332 & 11.03 & 0.752746 & 1.057756 & $5.345 \mathrm{E}+05$ & $1.815 \mathrm{E}-03$ & 0.1388 & 0.1035 & 0.479 & 0.858 & 2.909 \\
0.160 & 0.090 & 0.01245 & 9.57 & 0.805484 & 0.919072 & $5.362 \mathrm{E}+05$ & $1.812 \mathrm{E}-03$ & 0.1383 & 0.0838 & 0.395 & 0.709 & 2.720 \\
0.140 & 0.084 & 0.01158 & 8.11 & 0.84852 & 0.779791 & $5.272 \mathrm{E}+05$ & $1.828 \mathrm{E}-03$ & 0.1379 & 0.0667 & 0.299 & 0.537 & 2.395 \\
0.120 & 0.078 & 0.01071 & 6.65 & 0.881854 & 0.640003 & $5.088 \mathrm{E}+05$ & $1.860 \mathrm{E}-03$ & 0.1373 & 0.0524 & 0.203 & 0.364 & 1.976 \\
0.100 & 0.072 & 0.00984 & 5.19 & 0.905485 & 0.4998 & $4.822 \mathrm{E}+05$ & $1.911 \mathrm{E}-03$ & 0.1367 & 0.0409 & 0.116 & 0.208 & 1.505 \\
0.080 & 0.066 & 0.00897 & 3.73 & 0.919414 & 0.359271 & $4.488 \mathrm{E}+05$ & $1.981 \mathrm{E}-03$ & 0.1359 & 0.0322 & 0.045 & 0.081 & 1.025 \\
0.060 & 0.060 & 0.0081 & 2.26 & 0.92364 & 0.218509 & $4.099 \mathrm{E}+05$ & $2.073 \mathrm{E}-03$ & 0.1350 & 0.0263 & -0.007 & -0.013 & 0.575 \\
& & Mean & 3.91 & Deg. & & & & & & 0.097 & 0.072 & 0.463 \\
& & & & & & & & & & Dsht & -0.005 & $\mathrm{kgf}$ \\
& & & & & & & & & & & Rudder thrust & 0.068 \\
\hline
\end{tabular}

Table 3 Powering table of large bulk carrier with a conventional rudder

\begin{tabular}{|c|c|c|c|c|c|c|c|c|c|c|c|c|}
\hline & & & & & model & ship & & Fixed & & & & \\
\hline & MS.No & & SRC $* * *$ & Lpp & 6 & 225 & $\mathrm{~g}$ & 9.80665 & \multicolumn{2}{|r|}{ no.of shafts } & 1 & \\
\hline & Date & & & $L w l$ & 6.12 & 229.5 & $\rho$ (sea) & 104.51 & & & & \\
\hline & S.No. & BULK & & B & 1.3 & 48.8 & $\nu$ (sea) & $1.189 \mathrm{E}-06$ & & & & \\
\hline & & & & alpha & 37.5 & & & & & & & \\
\hline & & & & & & & & & & & & \\
\hline Cond & Scantling & & $V_{s}(k t s)$ & $V_{s}(\mathrm{~m} / \mathrm{s})$ & $\mathrm{Fn}$ & $r w(e-3)$ & $\mathrm{Cw}_{w}$ & Rns & Cfs & Cts & $\mathrm{RT}(\mathrm{kg})$ & $E H P(k W)$ \\
\hline d & 13.425 & & 11.07 & 5.693 & 0.120 & 0.068 & $2.21 \mathrm{E}-05$ & $1.099 \mathrm{E}+09$ & $1.512 \mathrm{E}-03$ & $2.152 \mathrm{E}-03$ & 53818 & 3,005 \\
\hline $\operatorname{Disp}(\mathrm{m} 3)$ & 118,637 & & 11.99 & 6.167 & 0.130 & 0.1641 & $5.33 \mathrm{E}-05$ & $1.190 \mathrm{E}+09$ & $1.497 \mathrm{E}-03$ & $2.164 \mathrm{E}-03$ & 63499 & 3,840 \\
\hline S(naked) & 14,484 & & 12.91 & 6.642 & 0.140 & 0.3002 & $9.74 \mathrm{E}-05$ & $1.282 E+09$ & $1.483 \mathrm{E}-03$ & $2.190 \mathrm{E}-03$ & 74536 & 4,855 \\
\hline S(whole) & 14,765 & & 13.83 & 7.116 & 0.150 & 0.4638 & $1.51 \mathrm{E}-04$ & $1.374 \mathrm{E}+09$ & $1.470 \mathrm{E}-03$ & $2.227 \mathrm{E}-03$ & 86993 & 6,071 \\
\hline & & & 14.76 & 7.591 & 0.160 & 0.6324 & $2.05 \mathrm{E}-04$ & $1.465 \mathrm{E}+09$ & $1.459 \mathrm{E}-03$ & $2.266 \mathrm{E}-03$ & 100732 & 7,498 \\
\hline & & & 15.68 & 8.065 & 0.170 & 0.7734 & $2.51 \mathrm{E}-04$ & $1.557 \mathrm{E}+09$ & $1.448 \mathrm{E}-03$ & $2.298 \mathrm{E}-03$ & 115300 & 9,119 \\
\hline K & 0.31 & & 16.60 & 8.539 & 0.180 & 0.8443 & $2.74 \mathrm{E}-04$ & $1.648 E+09$ & $1.438 \mathrm{E}-03$ & $2.307 \mathrm{E}-03$ & 129813 & 10,871 \\
\hline $\mathrm{Ca}(\mathrm{dCf})$ & $1.50 \mathrm{E}-04$ & & & & & & & & & & & \\
\hline & & & $V_{s}(k t s)$ & $1-\mathrm{t}$ & $1-w t$ & eta- $r$ & 1-ws & eta-h & $\mathrm{T}$ & $\mathrm{Va}$ & $\mathrm{Kt} / \mathrm{J} 2$ & \\
\hline$D p(m)$ & 0.17 & & 11.07 & 0.836 & 0.600 & 0.990 & 0.691 & 1.210 & 64344 & 3.935 & 0.978 & \\
\hline $\mathrm{Dp}(\mathrm{Act})$ & 6.38 & & 11.99 & 0.836 & 0.600 & 0.990 & 0.691 & 1.210 & 75920 & 4.263 & 0.984 & \\
\hline & & & 12.91 & 0.836 & 0.600 & 0.990 & 0.691 & 1.210 & 89115 & 4.591 & 0.996 & \\
\hline wake $\mathrm{R}$. & 1.15 & & 13.83 & 0.836 & 0.600 & 0.990 & 0.691 & 1.210 & 104009 & 4.919 & 1.012 & \\
\hline eta-t & 0.980 & & 14.76 & 0.836 & 0.600 & 0.990 & 0.691 & 1.210 & 120435 & 5.247 & 1.030 & \\
\hline & & & 15.68 & 0.836 & 0.600 & 0.990 & 0.691 & 1.210 & 137853 & 5.574 & 1.044 & \\
\hline & & & 16.60 & 0.836 & 0.600 & 0.990 & 0.691 & 1.210 & 155205 & 5.902 & 1.049 & \\
\hline & & & & & & & & & & & & \\
\hline & & & & & & & & & & & & \\
\hline & & & $V_{s}(k t s)$ & $\mathrm{J}$ & $\mathrm{Kt}$ & $\mathrm{Ka}$ & eta-o & eta & $\mathrm{DHP}(\mathrm{kW})$ & $\mathrm{N}$ & $\mathrm{BHP}(\mathrm{kW})$ & \\
\hline & & & 11.07 & 0.437 & 0.1871 & 0.02346 & 0.555 & 0.6649 & 4519 & 84.7 & 4611 & \\
\hline & & & 11.99 & 0.436 & 0.1874 & 0.02349 & 0.554 & 0.6640 & 5784 & 91.9 & 5902 & \\
\hline & & & 12.91 & 0.435 & 0.1882 & 0.02356 & 0.553 & 0.6621 & 7333 & 99.4 & 7482 & \\
\hline & & & 13.83 & 0.432 & 0.1892 & 0.02365 & 0.550 & 0.6594 & 9207 & 107.1 & 9395 & \\
\hline & & & 14.76 & 0.430 & 0.1903 & 0.02376 & 0.548 & 0.6565 & 11422 & 114.9 & 11655 & \\
\hline & & & 15.68 & 0.428 & 0.1912 & 0.02384 & 0.546 & 0.6542 & 13939 & 122.6 & 14224 & \\
\hline & & & 16.60 & 0.427 & 0.1914 & 0.02386 & 0.546 & 0.6535 & 16635 & 130.0 & 16974 & \\
\hline
\end{tabular}




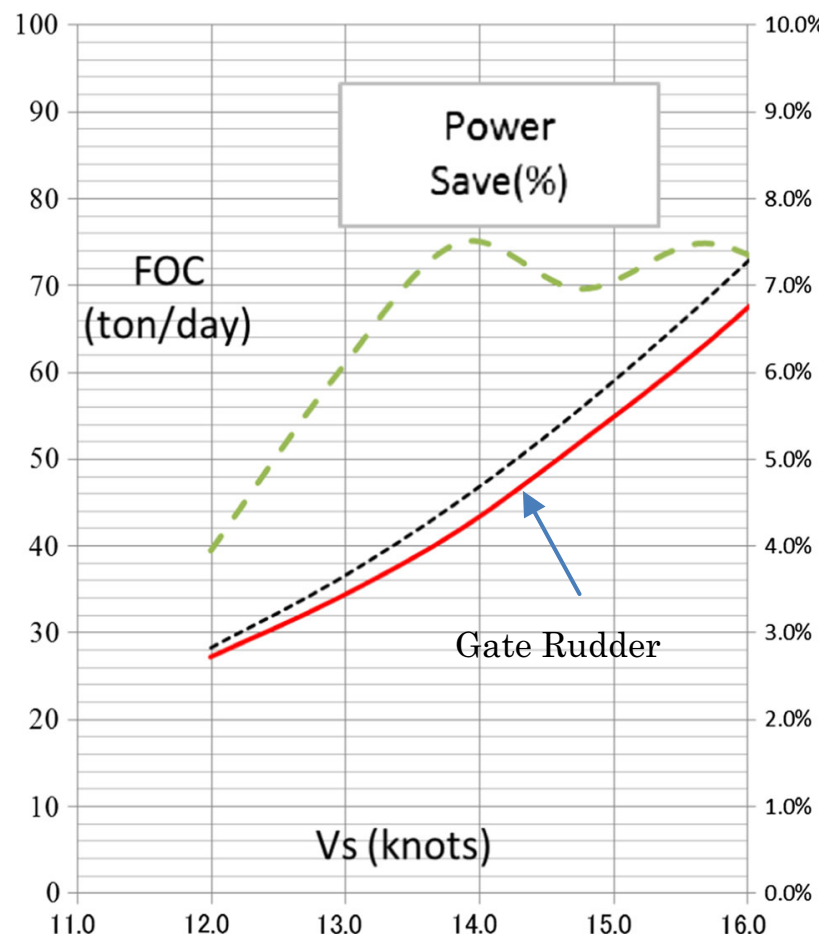

Fig. 10 Power savings by gate rudder

the rudder. In this study, the flow field was investigated using CFD (NEPTUNE) at each section of the gate rudder. The information on the normalized velocity, horizontal flow angles and rudder thrust obtained based on the above described method are shown in Fig. 8. This was followed by the design of each section in line with the optimum attack angle for specific horizontal position. Table 2 summarizes further details of the design calculations including rudder forces $F_{R X, Y}$ of the model based on Eqs. 1-8. In the same table, $F x$ and $F y$ are calculated by Eqs. 9 and 10

$F_{R X}(z)=L(z) \sin \psi(z)-D(z) \cos \psi(z)$
$F_{R Y}(z)=L(z) \cos \psi(z)+D(z) \sin \psi(z)$

\subsection{Resistance and propulsion tests}

The model test of a gate rudder was conducted at the large towing tank of NMRI with a $6 \mathrm{~m}$ long bulk carrier model. The NMRI tank is one of the largest towing tanks in the world (length $=400 \mathrm{~m}$, width $=18 \mathrm{~m}$, depth $=8 \mathrm{~m}$ ) and it is being used for various model tests including very large crude oil carriers and super high-speed vessels. Continuous upgrading of this facility since 2001 has been enhancing its capability to perform model tests under the conditions closer to actual sea states.

The ship model with the gate rudder was obtained by simply replacing the conventional rudder of an existing bulk carrier model with a gate rudder configuration by shifting the AP position further forward without any change of the stern form as shown in Fig. 9.

Table 3 shows the tank test results and Fig. 10 is the power curves obtained based on these results.

\subsection{Powering and fuel consumption analysis}

The power saving analysis of a ship with a new ESD device is one of the most difficult tasks for naval architects because the precise powering mostly depends on the available (co-relation or correlation) data between the model test and sea trial results of sister vessels or similar vessels. It is a well-known fact that the model test results can vary with the model basin if there is no standard procedure which is discussed and authorized among the towing tank facilities of the world. However, shipyards have been conducted the model tests based on their own standards which are not the same as other model basins. This is one of the main reasons why each shipyard has its own correlation factors.

SRC is the largest commercial tank in Japan and they have a long history for model testing and powering based on their know-how. Regarding the ship with a gate rudder, there might be a risk of error for powering prediction because of the lack of correlation between the model test and full-scale data. Therefore, the SRC has been selected for this study as a reliable model basin for model testing and powering. The powering was made based on their routine as shown in Eq. 11;

$$
\begin{aligned}
\mathrm{DHP} & =\frac{\mathrm{EHP}}{\eta_{D}}, \mathrm{EHP}=R \cdot V_{S} \\
R & =\frac{1}{2} C_{T} \rho V_{S}^{2} S_{W}, C_{T}=(1+k) C_{F}+C_{W}+\Delta C_{F} \\
\eta_{D} & =\frac{1-t}{1-w} \eta_{0} \eta_{R}
\end{aligned}
$$

The powering method is very close to the ITTC procedure except for the friction line and correlation factors, which are obtained by analyzing many sea trial results as well as the information obtained from many shipyards using the same procedure.

Based on the power estimation described above, the fuel consumption of both vessels was calculated using the Eq. 12,

FOC $($ ton $/$ day $)=24$ FOCR $(\mathrm{g} / \mathrm{kW} / \mathrm{h}) \mathrm{BHP} / 10^{6}$

$\mathrm{BHP}=\mathrm{DHP} / \eta_{t}$

where FOCR and $\eta_{t}$ is fuel consumption rate and transmission efficiency, respectively. 
Table 4 Powering table of large bulk carrier with a gate rudder

\begin{tabular}{|c|c|c|c|c|c|c|c|c|c|c|c|c|}
\hline & & & & & model & ship & & Fixed & & & & \\
\hline & MS.No & & SRC**** & Lpp & 6 & 225 & $\mathrm{~g}$ & 9.80665 & \multicolumn{2}{|r|}{ no.of shafts } & 1 & \\
\hline & Date & & & Lwl & 6.12 & 229.5 & $\rho$ (sea) & 104.51 & & & & \\
\hline & S.No. & BULK & & $B$ & 1.3 & 48.8 & $\nu$ (sea) & $1.189 \mathrm{E}-06$ & & & & \\
\hline & & & & alpha & 37.5 & & & & & & & \\
\hline & & & & & & & & & & & & \\
\hline Cond & Scantling & & Vs (kts) & $V_{s}(m / s)$ & $\mathrm{Fn}$ & $r w(e-3)$ & $\mathrm{Cw}$ & Rns & Cfs & Cts & $\mathrm{RT}(\mathrm{kg})$ & $\mathrm{EHP}(\mathrm{kW})$ \\
\hline d & 13.425 & & 11.07 & 5.693 & 0.120 & 0.032 & $1.06 \mathrm{E}-05$ & $1.099 \mathrm{E}+09$ & $1.512 \mathrm{E}-03$ & $2.126 \mathrm{E}-03$ & 52140 & 2,911 \\
\hline $\operatorname{Disp}(\mathrm{m} 3)$ & 118,637 & & 11.99 & 6.167 & 0.130 & 0.186 & $6.15 \mathrm{E}-05$ & $1.190 \mathrm{E}+09$ & 1.497E-03 & 2.157E-03 & 62097 & 3,756 \\
\hline$S($ naked) & 14,484 & & 12.91 & 6.642 & 0.140 & 0.194 & $6.42 \mathrm{E}-05$ & $1.282 E+09$ & $1.483 \mathrm{E}-03$ & $2.142 E-03$ & 71511 & 4,658 \\
\hline S(whole) & 14,484 & & 13.83 & 7.116 & 0.150 & 0.28 & $9.26 \mathrm{E}-05$ & $1.374 \mathrm{E}+09$ & $1.470 \mathrm{E}-03$ & $2.154 \mathrm{E}-03$ & 82554 & 5,761 \\
\hline & & & 14.76 & 7.591 & 0.160 & 0.464 & $1.53 \mathrm{E}-04$ & $1.465 \mathrm{E}+09$ & $1.459 \mathrm{E}-03$ & $2.200 E-03$ & 95921 & 7,140 \\
\hline & & & 15.68 & 8.065 & 0.170 & 0.575 & $1.90 \mathrm{E}-04$ & $1.557 \mathrm{E}+09$ & $1.448 \mathrm{E}-03$ & $2.222 \mathrm{E}-03$ & 109400 & 8,652 \\
\hline $\mathrm{K}$ & 0.3 & & 16.60 & 8.539 & 0.180 & 0.68 & $2.25 \mathrm{E}-04$ & $1.648 E+09$ & $1.438 \mathrm{E}-03$ & 2.244E-03 & 123840 & 10,371 \\
\hline $\mathrm{Ca}(\mathrm{dCf})$ & $1.50 \mathrm{E}-04$ & & & & & & & & & & & \\
\hline & & & Vs (kts) & $1-t$ & $1-w t$ & eta-r & $1-w s$ & eta-h & $\mathrm{T}$ & $\mathrm{Va}$ & & \\
\hline $\mathrm{Dp}(\mathrm{m})$ & 0.17 & & 11.07 & 0.880 & 0.725 & 0.970 & 0.779 & 1.129 & 59250 & 4.437 & & \\
\hline $\mathrm{Dp}(A c t)$ & 6.38 & & 11.99 & 0.880 & 0.728 & 0.970 & 0.783 & 1.124 & 70565 & 4.827 & & \\
\hline & & & 12.91 & 0.880 & 0.731 & 0.970 & 0.786 & 1.120 & 81262 & 5.219 & & \\
\hline wake R. & 1.075 & & 13.83 & 0.880 & 0.734 & 0.975 & 0.789 & 1.115 & 93811 & 5.615 & & \\
\hline eta-t & 0.980 & & 14.76 & 0.880 & 0.737 & 0.975 & 0.792 & 1.111 & 109001 & 6.014 & & \\
\hline & & & 15.68 & 0.880 & 0.740 & 0.978 & 0.796 & 1.106 & 124318 & 6.416 & & \\
\hline & & & 16.60 & 0.880 & 0.743 & 0.980 & 0.799 & 1.102 & 140728 & 6.821 & & \\
\hline & & & & & & & & & & & & \\
\hline & & & & & & & & & & & & \\
\hline & & & Vs (kts) & $\mathrm{Kt} / \mathrm{J} 2$ & J & $\mathrm{Kt}$ & $\mathrm{Kq}$ & eta-o & eta & $\mathrm{DHP}(\mathrm{kW})$ & & \\
\hline & & & 11.07 & 0.709 & 0.505 & 0.1808 & 0.02343 & 0.621 & 0.6797 & 4283 & & \\
\hline & & & 11.99 & 0.713 & 0.504 & 0.1813 & 0.02347 & 0.620 & 0.6760 & 5555 & & \\
\hline & & & 12.91 & 0.702 & 0.507 & 0.1802 & 0.02337 & 0.622 & 0.6753 & 6897 & & \\
\hline & & & 13.83 & 0.701 & 0.507 & 0.1801 & 0.02336 & 0.622 & 0.6764 & 8518 & & \\
\hline & & & 14.76 & 0.710 & 0.505 & 0.1809 & 0.02344 & 0.620 & 0.6719 & 10627 & & \\
\hline & & & 15.68 & 0.711 & 0.505 & 0.1811 & 0.02345 & 0.620 & 0.6710 & 12896 & & \\
\hline & & & 16.60 & 0.712 & 0.504 & 0.1812 & 0.02346 & 0.620 & 0.6694 & 15492 & & \\
\hline
\end{tabular}

For a realistic marine engine, $200 \mathrm{~g} / \mathrm{kw} / \mathrm{h}$ and 0.99 were used for the above parameters, respectively. The FOC reflects BHP directly and the power difference of both vessels is around $7-8 \%$.

The detailed calculation of powering can be seen in Tables 3 and 4.

\subsection{Rudder thrust measurements}

As the power curves show a 7-8 \% difference between two vessels, it is very clear that the new rudder system has different characteristics from the conventional rudders. To investigate the reason for this 7-8\% power reduction, the rudder forces and moment were measured for the vessel with fitted with the gate rudder.

The $F_{R X}(\mathrm{cal}), F_{R Y}(\mathrm{cal})$ and $N(\mathrm{cal})$ that appeared in Fig. 11 was calculated by Eqs. 13-15, respectively.

$$
\begin{aligned}
F_{R X}(\mathrm{cal})= & \int_{\text {bottom }}^{\text {top }} F_{R X}(z)^{\text {port }} \mathrm{d} z+\int_{\text {bottom }}^{\text {top }} F_{R X}(z)^{\text {starbord }} \mathrm{d} z \\
& -R_{\mathrm{SFT}}
\end{aligned}
$$




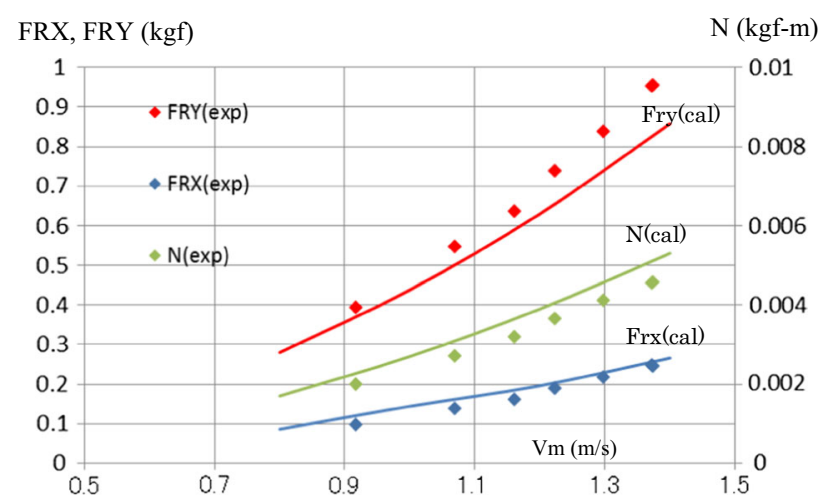

Fig. 11 Comparison of calculations and measurements for rudder forces

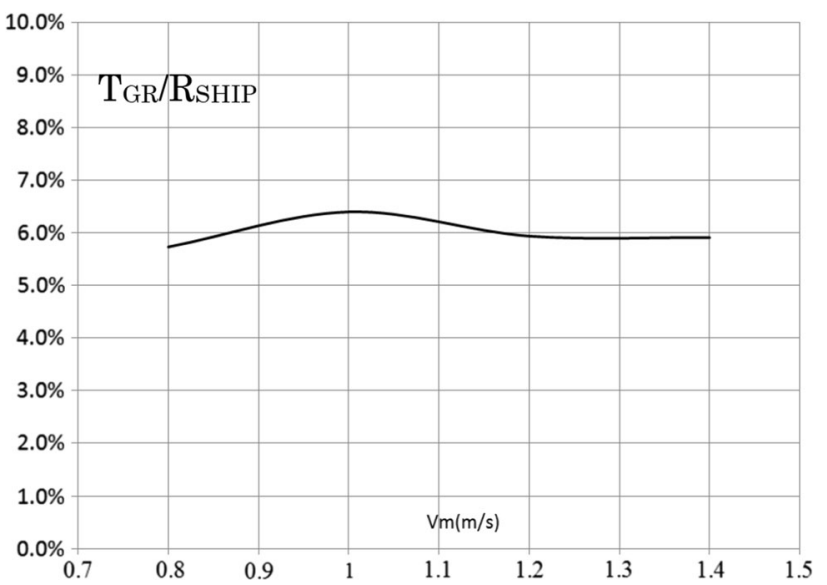

Fig. 12 Gate rudder thrust (\%) for hull resistance

$$
\begin{gathered}
F_{R Y}(\text { cal })=\int_{\text {bottom }}^{\text {top }} F_{R Y}(z)^{\text {port }} \mathrm{d} z-\int_{\text {bottom }}^{\text {top }} F_{R Y}(z)^{\text {starbord }} \mathrm{d} z \\
N^{\text {port }}(\text { cal })=\int_{\text {bottom }}^{\text {top }} F_{R X}(z)^{\text {port }} \mathrm{d} z \cdot l^{\text {port }} \mathrm{d} z \\
N^{\text {starbord }}(\text { cal })=\int_{\text {bottom }}^{\text {top }} F_{R X}(z)^{\text {starbord }} \mathrm{d} z \cdot l^{\text {starbord }} \mathrm{d} z
\end{gathered}
$$

where $l$ is a center of effort at each rudder section and given by Eq. 16.

$l=\left(X_{\mathrm{RP}} / C m(z)-0.35\right) \cdot C m(z)$

$X_{\mathrm{RP}}$ is the distance of rudder post from the leading edge of each section.

It was found that the direction of $F_{R Y}$ is inward and toward to ship centerline. Therefore, total force of $F_{R Y}$ received by the vessel is negligibly small.

As shown in Fig. 12, thrust of the gate rudder amounts to $6 \%$ of the ship resistance. This implies that the power saving of the gate rudder is coming from mainly this rudder thrust because the thrust of the conventional rudder is negative (i.e., resistance).

\subsection{Cost-effectiveness}

At the beginning of the paper, it has been stated that the cost-effectiveness is very important for the new ESD. The cost estimation was made based on the previous study. Following assumptions were made for the estimations;

1. The vessel will be built as a new ship

2. Energy saving by the gate rudder will be between 3 and $8 \%$ depending on ship fullness

3. Bunker oil price is assumed as $0.333 \mathrm{k} \$ /$ ton

4. Two small rudders will be installed replacing a large conventional rudder

5. One additional rudder is considered for cost wise

6. The cost of rudder is estimated based on $3.75 \mathrm{k} \$ /$ ton

7. The cost of steering gear is estimated based on $0.67 \mathrm{k} \$ /$ ton-m

8. The cost of upgrading of the software for the new system was estimated as $25 \%$ of hardware.

As shown in Table 5, the return of investment (ROI) is $0.37-0.90$ which indicates a period of return, less than a year. These figures may vary depending on oil price, shipyards standard. However, the range of the fluctuations will be around $10 \%$ and the ROI of the gate rudder will be still attractive. 
Table 5 ROI calculation of gate rudder

\begin{tabular}{|c|c|c|c|c|c|c|c|c|c|c|}
\hline | & Lpp & $B$ & d & $\mathrm{CB} /(\mathrm{L} / \mathrm{B})$ & M/E Output & $70 \%$ & SFO & ton/day & days & ton/year \\
\hline CAPE & 300 & 50 & 18.3 & 0.145 & 18000 & 12600 & 180 & 54 & 300 & 16,330 \\
\hline COAL & 223 & 50 & 13.45 & 0.173 & 11760 & 8232 & 180 & 36 & 300 & 10,669 \\
\hline PANAMAX & 225 & 32.2 & 14 & 0.125 & 11000 & 7700 & 180 & 33 & 280 & 9,314 \\
\hline HANDY & 180 & 30 & 12.2 & 0.133 & 8000 & 5600 & 180 & 24 & 280 & 6,774 \\
\hline VLCC & 320 & 60 & 20.8 & 0.156 & 28000 & 19600 & 180 & 85 & 300 & 25,402 \\
\hline AFRA & 230 & 42 & 14 & 0.150 & 12000 & 8400 & 180 & 36 & 300 & 10,886 \\
\hline & & & & & & & & & & \\
\hline \multicolumn{11}{|c|}{ Additional Contruction } \\
\hline & & & & & & & & & & \\
\hline & Rudder Area & Rudder Weight & Cost of Rudder & St. Gear Capa & Cost of St. G & & & & & \\
\hline & $\mathrm{m}^{* * 2} 2$ & ton & $\mathrm{k} \$$ & ton-m & $\mathrm{k} \$$ & & & & & \\
\hline CAPE & 46 & 35 & 130 & 75 & 50 & & & & & \\
\hline COAL & 25 & 16 & 58 & 30 & 20 & & & & & \\
\hline PANAMAX & 26 & 17 & 62 & 32 & 22 & & & & & \\
\hline HANDY & 18 & 11 & 40 & 19 & 13 & & & & & \\
\hline VLCC & 55 & 46 & 171 & 102 & 68 & & & & & \\
\hline AFRA & 27 & 17 & 64 & 33 & 22 & & & & & \\
\hline & & & & & & & & & & \\
\hline & & & & & COST UP & & & & & \\
\hline & Power Save & FO save & FO Save & Rudder & \begin{tabular}{|l|l} 
ST. GEAR \\
\end{tabular} & System & DOCK & Total Cost Up & \begin{tabular}{|l} 
ROI(year) \\
\end{tabular} & \\
\hline & $\%$ & ton/year & K\$/year & $\mathrm{k} \$$ & $\mathrm{k} \$$ & $\mathrm{k} \$$ & $\mathrm{k} \$$ & $\mathrm{k} \$$ & & \\
\hline CAPE & 5.3 & 868 & 289 & 130 & 50 & 45 & 0 & 225 & 0.78 & \\
\hline COAL & 7.4 & 793 & 264 & 58 & 20 & 20 & 0 & 98 & 0.37 & \\
\hline PANAMAX & 3.7 & 349 & 116 & 62 & 22 & 21 & 0 & 104 & 0.90 & \\
\hline HANDY BC & 4.4 & 300 & 100 & 40 & 13 & 13 & 0 & 66 & 0.66 & \\
\hline VLCC OIL & 6.1 & 1,557 & 519 & 171 & 68 & 60 & 0 & 299 & 0.58 & \\
\hline AFRA OIL & 5.7 & 618 & 206 & 64 & 22 & 21 & 0 & 107 & 0.52 & \\
\hline
\end{tabular}

\section{Conclusion}

A new twin rudder system, which is named as "gate rudder" and working on different principles than the current ESDs, has been introduced as a new category of ESD. This study described the energy saving principles of the new device and evaluated its applicability on a large bulk carrier using experimental and numerical methods. The study also evaluated the cost-effectiveness of the proposed ESD. Based on the investigations, it was found that:

1. The new twin rudder system has the potential of energy savings up to 7-8 \%.

2. The accuracy of the design method for the new rudder system was confirmed by model tests and measuring the rudder thrust during the self-propulsion condition.

3. The return of investment of the new system based on the conventional powering estimation procedures can be as attractive as $0.37-0.9$ year.

4. The powering method used to evaluate the new ESD may have uncertainty that should be further investigated to scrutinize the above claimed energy saving figure.
5. The maneuverability and cavitation risks should be studied as a further work.

Open Access This article is distributed under the terms of the Creative Commons Attribution 4.0 International License (http://crea tivecommons.org/licenses/by/4.0/), which permits unrestricted use, distribution, and reproduction in any medium, provided you give appropriate credit to the original author(s) and the source, provide a link to the Creative Commons license, and indicate if changes were made.

\section{References}

1. Takekuma K, Kawamura A, Kawaguchi N, Tsuda S (1981) Development of reaction fin as a device for improvement of propulsive performance of high block coefficient ships. JASNAOE 150:343-360

2. Sasaki N, Nagamatsu S (1985) Development of the energy saving appendage for full ships. Sumitomo Tech Rev Rev 33:40-46

3. Schneekluth H (1986) Wake equalising ducts. The Naval Architect, London

4. Kitazawa T, Hikino M, Fujimoto T, Ueda K (1982) Increase in the propulsive efficiency of a ship by a nozzle installed just in front of a propeller. J Soc Naval Archit Jpn 184:73-78

5. Yamamori T, Fujimoto T, Miyamoto M, Nagahama M (2001) Application of overlaid grid method to numerical simulation of 
flow around ship equipped with super stream duct (SSD). J Kansai Soc Naval Archit 235:49-56

6. Masuko A, Koshiba Y, Ishiguro T (1998) Energy saving device for ships IHI-L. V. Fin. Ishikawajima Harima Eng Rev 38(6):392-397

7. Sasaki N (1998) Trend of energy saving devices of ships. JASME 33(9):623-633

8. Sasaki N, Aono T (1997) Development of energy saving device "SILD". Sumitomo Tech Rev Rev 135:47-50

9. Carton J (2012) Marine propellers and propulsion, 13.3. RudderBulb Fins Systems, Butterworth-Heinemann, p 341
10. Ouchi K, Tamashima M (1989) Research and development on PBCF (Propeller Boss Cap Fins). In: PRADS'89, October 1989

11. Kuroda M, Tsujimoto M, Sasaki N (2013) Analysis on onboard measurement data for the validation of the effect of the energy saving device STEP, Proceedings of PRADS2013, p 346-351

12. Sasaki N (2013) ZEUS and NOAH projects of NMRI, 3rd international symposium on marine propulsors, May 2013

13. Molland AF, Turnock SR (eds) (2007) Marine rudders and control surfaces. Boston, p 15

14. Schneekluth H, Betram V (1998) Ship design for efficiency and economy, 2nd Ed. Butterworth-Heinemann, Oxford 